\title{
LA DESFORMALIZACIÓN DEL PROCESO JUDICIAL DE FAMILIA E INFANCIA
}

[Deformalization of the Family and Childhood-Related Legal Proceedings]

\author{
Francesco Carretta Muñoz* \\ Pontificia Universidad Católica de Valparaíso, Chile
}

\begin{abstract}
RESUMEN
Se examina la noción de desformalización como uno de los mecanismos introducidos por la Ley $\mathrm{N}^{\circ} 19.968$ para lograr la adecuada tramitación del procedimiento de familia e infancia vigente en Chile desde el año 2005. Este primer enfoque pretende establecer las bases para una completa delimitación del concepto.

Palabras clave

Desformalización procesal - Procedimiento de familia - Procedimiento de infancia.
\end{abstract}

\begin{abstract}
The notion of deformalization as one of the mechanisms introduced by Act No. 19.968 is examined to ensure the correct handling of family and childhood proceedings in Chile, valid since 2005. This initial approach aims at establishing the grounds to have a thorough definition of the concept.

\section{KEYWORDS}

Procedural deformalization - Family related proceedings - Childhood-related proceedings.
\end{abstract}

RECIBIDO el 20 de enero y ACEPTADo 2 de mayo de 2014

* Doctor en Derecho por la Pontificia Universidad Católica de Valparaíso. Profesor agregado de la Facultad de Derecho de la Pontificia Universidad Católica de Valparaíso. Juez del Tribunal de Familia de Valparaíso. Dirección postal: Facultad de Derecho, Pontificia Universidad Católica de Valparaíso, Casilla 4055, Valparaíso, Chile. Correo electrónico: fcarretta@me.com. Este trabajo fue realizado en el marco y con el financiamiento del proyecto Fondecyt iniciación $\mathrm{N}^{\circ} 11130404$, titulado "Estudio sobre la desformalización del proceso judicial de familia e infancia, de cara a su adecuada interpretación y aplicación en la justicia de familia chilena", del cual el autor de este trabajo es su investigador responsable. El autor agradece las observaciones realizadas por los ayudantes de investigación de la Pontificia Universidad Católica de Valparaíso, Gabriela Palacios Vergara y Sebastián Vergara de la Rivera. 


\section{INTRODUCCIÓN}

El proceso, atendido su carácter instrumental, posee características distintivas según sea el derecho material que encause. Se comprende, por ejemplo, que si lo tutelado es el derecho de un infante que ha sido vulnerado, se requiera la mayor diligencia procesal para restablecer aquel derecho. De acuerdo a ello, las formas rituales, de vital importancia para el establecimiento de un debido proceso, se presentan de manera menos rígida en procedimientos de familia que en un litigio civil patrimonial, en favor de un avance más eficiente del iter procesal. A ello atiende precisamente la desformalización.

En Chile, a partir del año 2005 en el sistema procesal de familia se produce un cambio radical. Se transita desde un proceso escrito y enfocado sólo a los problemas de la niñez, a uno oral que abarca todas las materias de familia. En el cuerpo normativo que forjó el cambio (Ley $\mathrm{N}^{\circ}$ 19.968) se insertó un artículo noveno, el que expresamente previó la desformalización, pero en él no queda claro si se trata de un principio o el anuncio que la propia ley establece de lo que se verá en adelante en el apartado normativo.

Se comprende que si se trata de una u otra opción, o una tercera que considere ambas variantes que actúan complementariamente, estamos frente a opciones de importantes consecuencias prácticas. Por ello, si consideramos que se trata de un principio (dilucidando el contenido y ámbito de aplicación de los mismos) quizá podamos llegar a la conclusión que el juez puede crear trámites procesales en aquellos casos que existe un vacío legal y estos son necesarios, o interpretar la aplicación de las normas procesales de acuerdo a ello. Si se trata de una característica pre anunciada en el apartado legislativo o implícito en el conjunto de sus normas, no tenemos tal opción, puesto que la intención del legislador en dicho evento sólo ha sido explicitar las especiales características del procedimiento, pero sin dar mayores atribuciones al Juez.

En cualquier evento, es necesario saber o precisar los límites jurídicos de la desformalización. Ello por cuanto la vulgarización del vocablo, que se genera por la escasa comprensión de los operadores sobre su alcance, puede ocasionar graves faltas en el sistema. En consecuencia si consideramos que las partes poseen dentro del proceso imperativos específicos de conducta, estos pueden ser transgredidos si el instrumento en estudio se aplica incorrectamente. Una de las causas puede deberse a la intuitiva e inadecuada comprensión del mismo. Ha sucedido, por ejemplo, que en la tramitación de procedimientos orales de familia, algunos jueces desarrollan conductas oficiosas tales como la apertura de plazos especiales, diversos a los establecidos por el legislador, para la contestación de la demanda; o la no asignación de valor a la preclusión, lo que conlleva la apertura indefinida de etapas procesales.

De acuerdo a lo anterior, esta investigación considera dos aspectos fun- 
damentales: uno es el estudio de la forma procesal en correlación al derecho material, y el otro es la interacción de ellos y las categorías que el derecho (reglas y principios) ha introducido dentro de la relación jurídica procesal, en el marco de un proceso que busca asegurar la tutela de los derechos de la familia y la infancia.

Se debe considerar que, desde un tiempo a esta fecha, la doctrina procesal civil chilena ha centrado sus esfuerzos en la investigación de diversos aspectos de un proceso civil de orden patrimonial, sobre todo con la posible llegada de un nuevo Código Procesal Civil. Sin embargo, ha ignorado casi por completo lo que es un antecedente e, incluso, un ensayo de dicha reforma, cual es el procedimiento oral que actualmente se tramita ante los tribunales de familia que en ocasiones comparte características similares a un proceso civil.

Lo que el lector verá en este trabajo es un marco teórico general de la desformalización. Una segunda parte, que será publicada después, abarcará un examen comparativo y contrastante sobre el tópico, del proceso chileno con los procesos de familia italiano y español, más nuevos aportes doctrinarios y jurisprudenciales que permitan profundizar la materia. También se contempla exhibir los resultados de un estudio empírico sobre la utilización del instituto por parte de los jueces de familia de diversas regiones del país. La extensión de esta investigación y el actual desarrollo de las pruebas de campo ha hecho imposible publicar todos sus resultados en una sola oportunidad.

\section{LAS FORMAS EN SENTIDO PROCESAL CIVIL}

Las formas en sentido procesal (distingo válido si se tiene en cuenta que dicho vocablo tiene significación en diversos ámbitos del saber humano') se encuentran presentes durante toda la evolución del derecho procesal ${ }^{2}$. Su contenido actual puede abarcar dos direcciones: una, de carácter restringido, la cual considera que la forma es la cualidad que circunda el acto procesal y constituye su exteriorización; y la otra, que es amplia, se refiere a las condiciones de lugar y tiempo en que se realiza el acto procesal. Tales circunstancias, al no ser intrínsecas al acto, son en realidad las "formalidades" que están previstas por una norma jurídica a fin de condicionar el ejercicio

${ }^{1}$ Álvaro de Oliviera, Carlos Alberto, Del formalismo en el proceso civil, propuesta de un formalismo valorativo (Lima, Palestra Editores, 2007), pp. 29-35.

${ }^{2}$ Van Rhee, C. H. - Uzelac, Alan (editores), Public and Private Justice. Dispute Resolution in Modern Societies (Antwerpen - Oxford, Intersentia, 2007), pp. 31-38; Kochenborger Scaparo, Eduardo, O processso como instumento dos dreitos fundamentais, en Revista da Facultadade de Direito UFPR, 45 (2006), p. 171; Tiranti, V. E., Ricerche sulla struttura orgánica del processo civile (Pisa, Spoerri, 1904). 
de un órgano o de un agente ${ }^{3}$. Respecto de ellas hay una connotación negativa cuando degeneran en cortapisas burocráticas que impiden la eficiente y expedita administración de justicia ${ }^{4}$.

Sin embargo, su matriz fundamental está dada porque constituyen el freno a la consumación del arbitrio y la prevaricación por parte de la auto$\operatorname{ridad}^{5}$. Es por ello que se ha dicho que las formas son el más seguro fundamento para crear en el juez una aureola de imparcialidad ${ }^{6}$. De esta manera, éstas contienen las reglas que determinan de antemano el rito que encausa la actividad de los sujetos procesales, cuya dirección encuentra curso en la previa determinación legal de los imperativos que regulan sus conductas? Luego, el mayor número y complejidad de ellas está en directa relación con la naturaleza del derecho material que el procedimiento vaya a encausar y con la mayor expedición con la que un ordenamiento pretenda tutelar aquel derecho ${ }^{8}$. Sucede que un mayor y más complejo número de formas tiende a ralentizar el devenir procesal, pero también garantiza de mejor manera el valor de seguridad jurídica que en ellas está envuelto\%. Entonces el legislador, frente a la disyuntiva, debe ser cauteloso en optar su flexibilización pues al tomar una decisión sobre el particular deberá dejar de lado las ventajas propias de su establecimiento. En otras palabras, puede gestarse en aquella elección un foco de arbitrariedad judicial ${ }^{10}$ o de mala fe por parte de los litigantes ${ }^{11}$.

${ }^{3}$ Alváro de Oliviera, Carlos Alberto, cit. (n. 1), pp. 29-35.

${ }^{4} \mathrm{WACH}$, Adolf, Conferencias sobre la Ordenanza Procesal Civil (Lima, Ara, 2006), p. 211.

${ }^{5}$ Troller, Alois, Dos fundamentos do formalismo processual civil (Porto Alegre, Sergio Antonio Fabris, 2009), pp. 217-222.

${ }^{6}$ Ibíd., p. 108.

${ }^{7}$ Ferruccio, Tomasseo, Appunti di diritto processuale civile. Nozioni introdutive (Torino, Giappichelli, 2000), p. 69.

${ }^{8}$ Marinoni, Luiz Guilherme - Pérez Ragone, Álvaro - Núñez OJeda, Raúl E., Fundamentos del proceso civil: hacia una teoría de la adjudicación (Santiago, Abeledo Perrot, 2010), pp. 110 -111

${ }^{9}$ Ibíd., pp. 115 -120. Sobre el particular, véase: GuZmán BRITo, Alejandro, La seguridad y certeza jurídica a través de la historia del Derecho, en Derecho y seguridad juridica, colección seminarios, 6 (Santiago, Universidad de Chile, 1983); GEIGER, Theodor, Estudios de sociología del Derecho (s.l., Fondo de Cultura Económica, 1983), pp. 91- 93. Henkel, Heinrich, Introducción a la fllosofía del derecho (Madrid, Taurus, 1968); PEREZ LuÑo, Antonio, La seguridad jurídica (Barcelona, Ariel, 1991).

${ }^{10}$ Véase: Cordopatri, Francesco, L'abuso del processo (Milano, Cedam, 2000); CARretta Muñoz, Francesco, La simetría de la relación adjetiva civil y el abuso procesal de los jueces, en Revista de Derecho de la Pontificia Universidad Católica de Valparaíso, 38 ( $1^{\mathrm{er}}$ semestre, 2012), pp. 325-341; PICARDI, Nicola, La responsabilità del giudice: la storia continua, en Rivista di Diritto Processuale, 1 (Milano, Cedam, 2007), pp. 295-306.

${ }^{11}$ Taruffo, Michele, L'abusso del processo: profili comparatistici, en Revista do Pro- 
Pensemos en una notificación que está cubierta de ciertos mecanismos que acrecientan su legitimidad en directa relación con la esencia del valor que resguardan: el emplazamiento como presupuesto necesario de un debido proceso. Así, no es casual que la notificación personal de la primera gestión en juicio sea practicada por un ministro de fe, a viva voz, con determinados requerimientos en su estampe físico y el lugar donde se ejecuta, porque cada particularidad pone cortapisas a la falsedad en la práctica de la misma. Si eliminamos algunos de dichos eslabones, como sucede en un proceso desformalizado, la seguridad de su producción queda de alguna manera mermada ${ }^{12}$. Es por ello que no se trata de asumir a la desformalización como la panacea de todos los procesos y sólo puede reservarse para aquellos que, por lo esencial de los derecho tutelados, sea razonable asumir riesgos.

\section{NATURALEZA DE LA DESFORMALIZACIÓN}

La desformalización en un sistema continental, donde prima el principio de la legalidad ${ }^{13}$, se puede gestar a través de dos vías. Una, que es aquella que acontece en Chile según se intentará demostrar en este estudio, se produce cuando legislador la presupone y después la describe expresamente en las hipótesis normativas (regla de técnica procesal), especificando la manera que en cada caso aquella se desarrollará. En este evento se comprende que naturalmente el radio de acción del juez quedará circunscrito a dichas hipótesis, lo que a su vez dice relación con el extenso tema de las facultades del juez y la confianza en la magistratura en un sistema donde alguna vez se pretendió que el juez sólo fuese un portavoz de la ley ("bouche de la loi") ${ }^{14}$. La otra se produce cuando la ley introduce un principio que permite al Juez intervenir dentro de un determinado contexto que, dada la amplitud de situaciones que pretende abarcar tal categoría jurídica ${ }^{15}$, presupone una mayor libertad y autonomía al juez en la posible alteración del iter procesal ${ }^{16}$.

ceso, 96 (1999), pp 151-169. Truffo, Michele - Hazard, Geoffrey (editores), Abuse of Procedural Rights: Comparative Standards of Procedural Fairness (New Orleans, Tulane Law School, 1999), pp. 35-52.

${ }^{12}$ Véase: Corte de Apelaciones de Valdivia, sentencia rol N 50-2011, dictada el 29 de marzo de 2011 (ID LegalPublishing 48543); Corte de Apelaciones de Rancagua, sentencia rol No 144-2008, dictada el 19 de mayo 2008 (ID LegalPublishing 39063).

${ }^{13}$ Pedraz, Ernesto, Organización judicial y Ministerio Fiscal, en Revista de Derecho de la Universidad Austral de Chile, 6 (1995), p. 41.

${ }^{14}$ Van Rhee, C. H. - Uzelac, Alan (editores), cit. (n. 2), pp. 55-73; TARello, Giovanni, Storia della cultura giuridica moderna (Bologna, Il Mulino, 1976), II, pp. 262-298.

${ }^{15}$ Peyrano, Jorge W. (director), Principios procesales (Buenos Aires, Rubinzal Culzoni, 2011), I, pp. 71-87.

${ }^{16}$ Hunter Ampuero, Iván, Poderes del juez civil: algunas consideraciones a pro- 
Si se opta por un principio, aparte de lo dicho, deben tenerse en cuenta una serie de tópicos de relevancia teórica y práctica. Uno de ellos dice relación con la función que estos cumplen en una disciplina a la que se le ha atribuido un carácter meramente instrumental ${ }^{17}$. Para comprenderlo se debe tener en cuenta que, no obstante que es indudable que el proceso es un instrumento que sirve al derecho de fondo, ello no obsta a que en su interior se desarrollan una serie de aspectos dinámicos ${ }^{18}$. Estos patrones son las conductas que los sujetos de la relación ejercen para dar progresión y sustento al procedimiento como cauce del derecho material que en él se vierte ${ }^{19}$. Estas son categorizadas jurídicamente como cargas, deberes y obligaciones que subsisten en interacción unas con otras ${ }^{20}$.

La progresión descrita posee a su vez parámetros que le dan al fenómeno señalado un cauce adecuado, que nacen desde el ordenamiento jurídico ${ }^{21}$. Es aquí donde el legislador inserta principios de forma directa o implícitamente, cuyo radio de acción puede cubrir un amplio espectro de situaciones ${ }^{22}$. Pero no podemos confundir los principios que poseen un sustento normativo, de aquellas directrices que dan forma a los diversos sistemas procesales, cuya elaboración es incluso inconsciente y obedece a una serie de factores políticos y culturales que, atendida su escasa certeza, no hacen posible aplicarlos directamente a la resolución de un conflicto ${ }^{23}$.

Los principios, funcionan de la misma forma que opera cualquier otra norma, por lo que deben ser elegidos, interpretados y aplicados exactamente igual que cualquier disposición ${ }^{24}$. También se les concede una función conser-

pósito del juez de familia, en Revista de derecho de la Universidad Austral de Chile, 20 (2012) 1, pp. 211-212.

${ }^{17}$ Luiso, Francesco, Diritto processuale civile (Milano, Giuffrè, 2007) p. 6; MANDRIOLI, Crisanto, Corso de diritto processuale civile (Torino, Giappichelli, 2007), I pp. 34-36; Proto Pisani, Andrea, Lezioni di diritto processuale civile (Napoli, Jovene, 1996), p. 34.

${ }^{18}$ Véase: CARretta, Francesco, Deberes procesales de las partes en el proceso civil chileno: Referencia a la buena fe procesal y al deber de coherencia, en Revista de Derecho de la Universidad Austral de Chile, 21 (2008) 1, pp. 101-127.

${ }^{19}$ Calamandrei, Piero, Proceso y democracia (Lima, Ara, 2006), p. 174.

${ }^{20}$ Lent, Friedrich, Obblighi e oneri nel proceso civile, en Rivista di Diritto Processuale, 9 (1954), pp. 150-158; Redenti, Enrico, Diritto proccesuale civile (Milano, Giuffrè, 1957), I, pp. $120-125$.

${ }^{21}$ Alexy, Robert, Teoría de la argumentación jurídica (Madrid, Centro de Estudios Políticos, 1997), p. 249.

${ }^{22}$ Ibíd., p. 26.

${ }^{23}$ Chase, Oscar, Law, Culture, and Ritual, Disputing Systems in Cross-Cultural Context (Nueva York, New York University Press, 2005), p. 31.

${ }^{24}$ Aragoneses, Pedro - Guasp, Jaime, Derecho procesal civil (Navarra, Aranzadi, 2006), I, p. 77. 
vadora, con la que se mantendría la rectitud del orden jurídico, y una función integradora ${ }^{25}$, destinada a cubrir las lagunas legales en pos de mantener la plenitud del ordenamiento jurídico, no existiendo clausura de una función por sobre la otra. Contribuyen de esta manera, a obtener la hermeticidad y armonía del orden jurídico, aunque no del todo, puesto que no es posible eliminar todas las contradicciones ni colmar todos los vacíos que puedan existir $^{26}$. Por último, se debe tener presente que estos se pueden extraer de la legislación cuando todas las disposiciones desde un punto de vista teleológico intentan solucionar una misma cuestión fáctica, de manera tal que frente a la falta de norma específica que regule un asunto, se pueda aplicar aquella misma razón subyacente a todas ellas. Pero también de forma más segura es el propio legislador quién consigna expresamente los principios para facilitar al intérprete la ordenación adecuada de las soluciones ${ }^{27}$. Luego, si se tiene en cuenta el radio de aplicación descrito, se ha de ser cuidadoso en su aplicación o instauración tácita (desprendida de un conjunto de normas) al que muchos operadores, atendido el sustrato de sentido común que poseen ${ }^{28}$, se pueden sentir tentados. Aquello, puede abrir paso a su vulgarización, fenómeno que aparte de incentivar una aplicación indiscriminada e incorrecta de tales, trae confusión al derecho y al sistema jurídico como denunciara Tarello hace ya bastantes años ${ }^{29}$.

\section{LA DESFORMALIZACIÓN EN OTRAS RAMAS DEL DERECHO}

Es importante señalar que la posibilidad de flexibilizar las formas rituales también está presente en el derecho procesal penal ${ }^{30}$.

La desformalización de las actuaciones del Ministerio Público, en la fase de investigación, es una de las principales características del proceso penal chileno y está contemplada en los artículos 180 inciso 1 y $181 \mathrm{CPP}$. Aquello tiene directa relación con el trámite de la Formalización en sede punitiva como la manera de informar el hecho de la investigación a un sujeto, o más bien, que una investigación sin sede judicial, a partir de ese punto, se

${ }^{25}$ Marinoni, Luiz Guilherme - Pérez Ragone, Álvaro - Núñez Ojeda, Raúl E., cit. (n. 8), pp. 30-34.

${ }^{26}$ Aragoneses, Pedro - Guasp, Jaime, cit. (n. 24), p. 77.

${ }^{27}$ Couture, Eduardo, Fundamentos del derecho procesal civil (Buenos Aires, Depalma, 1993), p. 182.

${ }^{28}$ TARuffo, Michele, Senso comun, experiencia e ciéncia no raciocinio do juiz, en Revista de la Universidad Federal do Paraná (2001) p. 10.

${ }^{29}$ Véase: TARello, Giovanni, Sul problema della crisi nel diritto (Torino, Giappichelli, 1957).

${ }^{30}$ Carocca Pérez, Alex, El nuevo sistema procesal penal (Santiago, LexisNexis, 2004), p. 27. 
judicializa mediante un proceso que constituirá la certeza de los derechos y obligaciones de los intervinientes involucrados en ella.

También se habla de un principio de desformalización o desjudicialización de la justicia penal juvenil donde el sistema tiende a buscar alternativas a la aplicación de una sanción penal a través de salidas alternativas regladas. Con ello se intenta evitar la sanción como una cuestión que posteriormente tenderá a la estigmatización del infractor juvenil. En ese sentido la desformalización se toma como una flexibilización del derecho penal en su forma más clásica o retributiva ${ }^{31}$.

Se ha forjado la tesis sobre la "desformalización de la constitución" cuando se pretende que la Constitución cumpla una función por encima a la que le es comúnmente asignada como lo es fijar los límites del poder del Estado frente a la libertad civil, sino que se le vincula a valores superiores al derecho que se orienta a establecer un orden jurídico justo ${ }^{32}$.

La Ley $\mathrm{N}^{\circ} 19.880$, que establece bases de los procedimientos administrativos que rigen los actos de los órganos de la administración del Estado, también contempla la desformalización de los procedimientos, o como lo denomina la propia ley en su artículo 13: "Principio de la no formalización". Este principio implica, conforme lo dispone el inciso $1^{\circ}$ : "El procedimiento debe desarrollarse con sencillez y eficacia, de modo que las formalidades que se exijan sean aquéllas indispensables para dejar constancia indubitada de lo actuado y evitar perjuicios a los particulares".

En el ámbito laboral, también se habla de la desformalización de los procedimientos, así, por ejemplo, se señala en fallo dictado por la Corte de Apelaciones de Santiago: "Que es hoy en dia un principio rector en el derecho procesal el de su desformalización que, en la especie requiere justamente decir que no es necesario para la eficacia de la acción que se cumpla con la ritualidad de menciones que aunque no explicitadas son inherentes a las instituciones controvertidas" 33 .

\section{DERECHO INTERNACIONAL}

El Convenio europeo sobre el ejercicio de los derechos del niño (Estrasburgo, 1996), también llamado "Convención sobre el ejercicio de los derechos del

${ }^{31}$ Véase: Aguirrezabal Grunstein, Maite - Lagos Carrasco, Gladys - Vargas Pinto, Tatiana, Responsabilidad penal juvenil: hacia una "justicia individualizada”, en Revista de Derecho de la Universidad Austral de Chile, 22 (2009) 2, pp. 137-159.

${ }^{32}$ De Julios Campusano, Alfonso (editor), Ciudadanía y derecho en la era de la globalización (Madrid, Dykinson, 2007), pp. 61-77.

${ }^{33}$ Corte de Apelaciones de Santiago, sentencia rol No 4331-1998, dictada el 17 de marzo de 1999 (ID LegalPublishing 20677). Rechaza recurso de casación en la forma que se fundó en la causal de ultra petita. 
niño" nace, según se establece en su preámbulo, en virtud del mandato del artículo 4 de la Convención de derechos del niño. Aquel instrumento precisa la forma de promover y garantizar los derecho adjetivos de un menor ${ }^{34}$, considerándose a éste, en consecuencia, como un sujeto procesal, independiente de su representación ${ }^{35}$. Lo anterior ha llevado a algunos autores a decir que, en virtud de este acuerdo, existe un verdadero derecho procesal del menor ${ }^{36}$, acentuando de esta manera la especial y completa tutela adjetiva de los niños que en dicho tratado se señala. Sin perjuicio de ello, en dicho instrumento internacional no se observa ningún apartado que incluya la posibilidad de desformalizar el proceso, o de flexibilizar sus formas o trámites, ni expresa ni tácitamente. En él se apuesta a la rapidez en la toma de decisiones judiciales sobre cuestiones relacionadas a la protección de la infancia, como atributo diferenciador del procedimiento ${ }^{37}$. El artículo 7 consagra el deber de los órganos judiciales de actuar prontamente para evitar retardos inútiles y asegurar una ejecución rápida de las decisiones judiciales. Conjuntamente se ha establecido la posibilidad de actuar de oficio en caso de extrema urgencia (art. 8).

\section{MARCO LEGAL}

Para analizar lo que ha sucedido en la justicia de familia en Chile hay que partir de la base que ésta tuvo un cambio radical a partir del año 2005. Se pasó, sin previa gradualidad, desde una multiplicidad de procedimientos escritos tramitados en tribunales civiles ordinarios para materias de familia en general y uno en tribunales especiales exclusivo para menores en riesgo social y material, a la instauración de un procedimiento oral, en un solo tribunal, que abarca todas las materias relacionadas al derecho de familia e infancia.

En principio, atendida la envergadura del cambio, hubo innumerables problemas debido a la súbita instauración del sistema, que llevaron a sucesivas modificaciones para optimizarlo. Así, en el transcurso de 9 años a partir de su inicio, todos los esfuerzos se han concentrado en introducir cambios de orden administrativo que, finalmente, han cristalizado en un procedimiento que ha disminuido considerablemente los tiempos de tramitación efectiva. No obstante, se han dejado de lado el análisis de aspectos adjetivos sustanciales que producen problemas jurídicos de envergadura. Uno de ellos

${ }^{34}$ Vargas Pavez, Macarena - Correa Camus, Paula, La voz de los niños en la justicia de familia de Chile, en Ius et Praxis, 17 (2011) 1, p. 186; MAIER, Julio, Los niños como titulares del derecho al debido proceso, en Justicia y Derechos del Niño, 2 (Buenos Aires, 2000), pp. 9-18.

${ }^{35}$ Magno, Giuseppe, Il minore come soggetto processuale, commento alla convenzione europea sull'esercizio dei diritti dei fanciulli (Milano, Giuffrè, 2001), pp. 55-77.

${ }^{36}$ FADIGA, Luigi, La Convenzione europea sull esercizio dei diritti dei fanciulli e la legge di ratifica (l.20 marzo 2003 n. 77) (2010) [visible en internet: en: www.juidicium.it]

${ }^{37}$ Magno, Giuseppe, cit. (n. 35), p. 133. 
es la desformalización (artículo 9 Ley $\mathrm{N}^{\circ} 19.968$ ) presente en el apartado normativo desde el inicio, en el siguiente tenor: "Principios del procedimiento. El procedimiento que aplicarán los juzgados de familia será oral, concentrado $y$ desformalizado. En él primarán los principios de la inmediación, actuación de oficio y búsqueda de soluciones colaborativas entre partes."

Si se observa con detención, la redacción de esta norma no menciona dentro del elenco de principios que establece (3) a la desformalización, pues antes del punto seguido, parece referirse a una de las tres particularidades del procedimiento. Así, el primer inciso de la misma, pre anuncia lo que el operador verá implícito en el cuerpo legislativo, mientras que el segundo señala las directrices presentes en aquel. Tampoco en la Convención de derechos del niño suscrita por Chile el año 1990 hay indicio alguno sobre la desformalización como una de las vías de tutelar de mejor forma los derechos de los niños ${ }^{38}$. Pero este argumento ceñido a la letra no se agota allí, la historia fidedigna del establecimiento de la ley que presentó varias aristas ${ }^{39}$ nos da mayores luces sobre el particular. En ella quedó plasmado que previamente se consideró la inserción del siguiente artículo 10: "Desformalización. En silencio de la ley, el juez determinará la forma en que se verificarán las actuaciones y, en esta tarea, como en la de interpretar las normas del procedimiento, tendrá siempre presente que su objetivo es el adecuado resguardo de los derechos reconocidos por la ley y la más pronta y justa decisión de la controversia".

Este proyecto de artículo luego se eliminó porque se estimó que la propuesta, no incidía en un tema de interpretación de la ley procesal, sino de creación normativa, lo que incursiona en atribuciones propias del legislador y no del juez de familia ${ }^{40}$. Se temió que el juez pudiese crear trámites o formas novedosas que pueden atentar contra las facultades propias del ente legislativo. En consecuencia, considerando el actual tenor de la norma en comento, quedó claro que a lo que se refiere el apartado normativo con la desformalización, no es un principio.

\section{JURISPRUDENCIA}

La Corte Suprema ha señalado que: "el propósito de la desformalización, cual es impedir que fórmulas sacramentales obstaculicen la prosecución del

${ }^{38}$ Véase: D’Antonio, Hugo, Convención sobre los derechos del niño, comentada y anotada exegéticamente, jurisprudencia nacional y extranjera (Buenos Aires, Astrea, 2001).

${ }^{39}$ Turner Saelzer, Susan, Los tribunales de familia, en Ius et Praxis, 8 (2002) 2, pp. 413-443.

${ }^{40}$ Historia de la ley 19.968 que crea los Tribunales de Familia, segundo informe Comisión de Constitución, discusión en particular (Valparaíso, 2004) p. 1057 [disponible en http://www.bcn.cl/histley/lfs/hdl-19968/HL19968.pdf]. 
juicio, no importa la absoluta ausencia de formas procesales para la realización de actuaciones u el cumplimiento de las diligencias judiciales que ejecutan un debido proceso" 41 . Como queda de manifiesto, si bien el máximo tribunal intentó precisar los márgenes del concepto y fue cautelosa en mencionar que se trata o no de un principio, lo escueto del razonamiento no ha permitido delinear desde la mayor o menor eficacia de un precedente horizontal o de autoridad ${ }^{42}$ los contornos de la desformalización. Prueba de ello es que los tribunales inferiores han insistido en tratar a la desformalización como un principio con las consecuencias que de ello se sigue ${ }^{43}$. En ese contexto jurisprudencial, no se tiene claridad si en virtud de la desformalización se pueden pasar por alto aspectos rituales claramente establecidos en la ley (plazos, notificaciones, etc.); si existe la posibilidad que los jueces efectúen interrogaciones a las partes en forma paralela a las audiencias, incluso antes de las mismas, sobre aspectos vinculados al objeto del litigio; que anulen actuaciones que estimen viciadas, contra la aplicación estricta de los presupuestos de la nulidad procesal; cuál es el valor de la preclusión en dichos procesos ${ }^{44}$, etcétera. A lo anterior se debe sumar que las decisiones judiciales en Chile como en otros sistemas continentales ${ }^{45}$ son variables, contradicto-

${ }^{41}$ Corte Suprema, sentencia dictada el 30 de octubre de 2007; BARrientos Grandon, Javier, El código de la familia (Santiago, Legalpublishing, 2009,), p. 556.

${ }^{42}$ Sobre el particular, véase: Accatino, Daniela, El precedente judicial en la cultura jurídica chilena, en Anuario de Filosofía Jurídica y Social, 20 (2002), pp. 559 - 582.

${ }^{43}$ Corte de Apelaciones de Valparaíso, sentencia rol N ${ }^{\circ} 375-2008$, (Repertorio, 2010, p. 662); Corte de Apelaciones de Santiago, sentencia rol No 4331-1998, dictada el 17 de marzo de 1999 (ID LegalPublishing 20677); Corte de Apelaciones de Puerto Montt, sentencia dictada el 30 de agosto de 2010 (ID LegalPublishing 47003); Corte de Apelaciones de San Miguel, sentencia rol No 415-2010, dictada el 4 de octubre de 2010 (ID Westlaw Chile CL/JUR/8075/2010); Corte de Apelaciones de San Miguel, sentencia rol No 218-2010, dictada el 10 de octubre de 2010 (ID Westlaw Chile CL/ JUR/2564/2010); Corte de Apelaciones de Concepción, sentencia rol No 433-2009, dictada el 22 de abril de 2010 (ID Westlaw Chile, CL/JUR/2746/2010); Corte de Apelaciones de Concepción, sentencia rol No 2239-2008, dictada el 28 de agosto de 2009 (ID Westlaw Chile, CL/JUR/667/2009); Corte de Apelaciones de Valparaíso, sentencia rol N $\mathrm{N}^{\circ} 375-2008$, dictada el 9 de octubre de 2008 (ID Westlaw Chile, CL/ JUR/3744/2008; Corte de Apelaciones de Punta Arenas, sentencia rol N 79-2007, dictada el 10 de diciembre de 2007 (ID Westlaw Chile, CL/JUR/251/2007); Corte de Apelaciones de Santiago, sentencia rol No2916-2007, dictada el 30 de octubre de 2007 (ID Westlaw Chile CL/JUR/121/2007).

${ }^{44}$ Tesoriere, Giovanni, Contributo allo studio delle preclusioni nel proceso civile (Padova, Cedam, 1983).

${ }^{45}$ Sobre el particular, véase: CHIARLONI, Sergio, Un mito reexaminado. Notas comparativas sobre la autoridad del precedente jurisprudencial, en Revista peruana de derecho procesal, 7 (2004); MARINONI, Luiz Guilherme, Aproximación critica entre las juris- 
rias e impredecibles. La falta de un precedente obligatorio permite plantear indefinidamente muchas discusiones jurídicas, sin que exista un límite que provenga de la existencia de una doctrina jurisprudencial sobre cierto tema, así, no es posible prever, de un modo razonable, el contenido final de la decisión para casos análogos, de manera que exista un criterio claro al cual atenerse y que se pueda hacer valer ${ }^{46}$. En ese panorama, el aporte dogmático sobre el punto resulta fundamental.

\section{CONCLUSión}

Esta primera mirada al instituto objeto de esta indagación permite elaborar tres hipótesis: $i$ ) que la ley en ningún caso señala que la desformalización sea un principio jurídico; $i i$ ) que, pese a lo anterior, los jueces de familia la entienden como tal, y iii) que la desformalización es una característica inherente a un procedimiento que busca la tutela de los derechos de la familia y la infancia.

Es más coherente con el ordenamiento jurídico aquella elección que éste mismo ha realizado al incorporar esta figura (artículo 9 Ley $\mathrm{N}^{\circ} 19.968$ ) como un dispositivo de técnica procesal. Ello se refleja en varios mecanismos que el procedimiento de familia comprende, donde se aprecia cierta flexibilidad, como en el caso de las notificaciones, por ejemplo. Flexibilidad especialmente notoria si se compara con el sistema procesal civil patrimonial. Conforme a esta interpretación, y no aquella que la considera como un principio, se deja de lado la amenaza a la seguridad jurídica y a la intromisión del órgano judicial en materias que son propias del legislador. Se evita, por tanto, la vulgarización del concepto y se contribuye a la correcta correspondencia del régimen democrático.

Para cerrar este estudio y comprobar las hipótesis expuestas, como se dijo en la introducción, en una segunda parte se consignarán mayores fundamentos teóricos en base al derecho vigente y comparado con el objeto de obtener una mejor profundización y dogmatización de las ideas expuestas. También se darán a conocer los resultados de una prospección elaborada mediante metodología cualitativa, de acuerdo a una muestra tomada a jueces de familia de diversas regiones del país, sobre la forma como entienden y aplican esta figura.

dicciones del "civil law" y del "common law" y la necesidad de respeto a los precedentes en Brasil, en Constitución y proceso (Lima, Ara, 2009), pp. 57-114.

${ }^{46}$ Romero Seguel, Alejandro, La jurisprudencia de los Tribunales como fuente del Derecho: una perspectiva procesal (Santiago, Editorial Jurídica de Chile, 2004), pp. 12-14. 


\section{BiBLIOGRAFÍA}

Pauletti, Ana Clara, Importancia actual de los principios del proceso civil, en Peyrano, Jorge W. (director), Principios procesales I (Buenos Aires, Rubinzal - Culzoni, 2011).

Accatino, Daniela, El precedente judicial en la cultura jurídica chilena, en Anuario de Filosofia Jurídica y Social, 20 (2002).

Aguirrezabal Grunstein, Maite - Lagos Carrasco, Gladys - Vargas Pinto, Tatiana, Responsabilidad penal juvenil:: hacia una "ac justicia individualizada', en Revista de Derecho de la Universidad Austral de Chile, 22 (2009) 22.

Alexy, Robert, Teoría de la argumentación jurídica, (Madrid, Centro de Estudios Políticos, 1997).

Alvaro de Oliveira, Carlos Alberto, Del formalismo en el proceso civil,, propuesta de un formalismo valorativo, (Lima, Palestra, 2007).

Aragoneses, Pedro - Guasp, Jaime, Derecho procesal civil (Navarra, Editorial Aranzadi S.A., 2006), I.

Barrientos Grandon, Javier, El código de la familia (Santiago, LegalPpublishing, 2009).

Calamandrei, Piero, Proceso y democracia (Lima, Ara, 2006).

Carocca Perez, Alex, El nuevo sistema procesal penal (Santiago, LexisNexis, 2004).

CARRETta MuÑoz, Francesco, La simetría de la relación adjetiva civily el abuso procesal de losjueces, en Revista de Derecho de la Pontificia Universidad Católica de Valparaíso, n.38, (1 ${ }^{\text {er }}$ semestre, 2012), pp. 325- -341.

Carretta, Francesco, Deberesprocesales de laspartes en el proceso civil chileno:: referencia a la buena fe procesaly al deber de coherencia, en Revista de Derecho de la Universidad Austral de Chile, 21 (2008) 1.

Chase, Oscar G, Law, Culture,, and Ritual,, Disputing Systems in Cross-Cultural Context (New York University Press, 2005).

ChIARloni, Sergio, Un mito reexaminado.. Notas comparativas sobre la autoridad del precedente jurisprudencial, en Revista Peruana de Derecho Procesal,, 7 (2004).

Cordopatri, Francesco, L' abuso del proceso (Milano, Cedam, 2000).

Couture, Eduardo, Fundamentos del derecho procesal civil (Buenos Aires, Editorial Depalma, 1993).

Cruz, Luz María, La desformalización de la constitución.. Notas sobre la critica de Ernst Forsthofft al ((neo)) constitucionalismo, en De Julios Campusano, Alfonso (editor), Ciudadania y derecho en la era de la globalización (Dykinson, Madrid, 2007).

D’Antonio, Hugo, Convención sobre los derechos del niño,, comentada y anotada exegéticamente,, jurisprudencia nacional y extranjera (Buenos Aires, Astrea, 2001).

FADIGA, Luigi, La Convenzione europea sull' esercizio dei diritti dei fanciulli e la legge di ratifica ((l..20 marzo 2003 n.. 77)) (2010) [visible en internet: en: www.juidicium.it].

Ferruccio, Tomasseo, Appunti di diritto processuale civile. . Nozioni introdutive (Torino, Giappichelli Editore, 2000).

Geiger, Theodor, Estudios de sociología del Derecho (s.l., Fondo de Cultura Económica, 1983).

Guzmán Brito, Alejandro, La seguridad y certeza jurídica a través de la historia del Derecho, en Derecho y seguridad jurídica, colección seminarios, 6 (Santiago, Universidad de Chile, 1983).

HenKel, Heinrich, Introducción a la filosofía del derecho (Madrid, Taurus Ediciones, 1968). 
Historia de la ley 19.968 que crea los Tribunales de Familia, segundo informe Comisión de Constitución, discusión en particular (Valparaíso, 2004) [, disponible en http:// www.bcn.cl/histley/lfs/hdl-19968/HL19968.pdf].

Hunter Ampuero, Iván, Poderes del juez civil: algunas consideraciones a propósito del juez de familia, en Revista de Derecho de la Universidad Austral de Chile, 201 (2012) 201.

Kochenborger Scarparo, Eduardo, O pProceso como instrumento dos direitos fundamentais, en Revista da Faculdade de Direito UFPR, 45 (Curitiba, 2006).

Lent, Friedrich, Obblighi e oneri nel proceso civile, en Rivista di Diritto Processuale,, 9 (1954).

Luiso, Francesco, Diritto processuale civile (Milano, Giuffrè, 2007).

Magno, Giuseppe, Il minore come soggetto processuale, commento alla convenzione europea sull'esercizio dei diritti dei fanciulli (Giuffrè, Milano, 2001).

MaIER, Julio, Los niños como titulares del derecho al debido proceso, en Revista Justicia y Derechos del Niño, 2 (Buenos Aires, 2000).

Mandrioli, Crisanto, Corso de diritto processuale civile (Torino, Giappichelli Editore, 2007), I.

Marinoni, Luiz Guilherme - Pérez Ragone, Álvaro - NúÑez Ojeda, Raúl E., Fundamentos del proceso civil:: hacia una teoría de la adjudicación (Santiago, Abeledo Perrot, 2010).

Marinoni, Luiz Guilherme, Aproximación critica entre las jurisdicciones del "civil law" $y$ del "common law" y la necesidad de respeto a los precedentes en Brasil, en Constitución y proceso (Lima, Ara, 2009).

Pedraz, Ernesto, Organización judicial y Ministerio Fiscal, en Revista de Derecho de la Universidad Austral de Chile, 6 (1995).

Pérez Luño, Antonio, La seguridad jurídica (Barcelona, Ariel, 1991).

PICARDI, Nicola, La responsabilità del giudice:: la storia continua, en Rivista di Diritto Processuale 1 (Milano, Cedam, 2007), pp. 295-306.

Proto Pisani, Andrea, Lezioni di diritto processuale civile (Napoli, Jovene editore, 1996).

Redenti, Enrico, Diritto proccesuale civile, (Milano, Giuffrè, 1957), I.

Romero Seguel, Alejandro, Lajurisprudencia de los Tribunales como fuente del Derecho: una perspectiva procesal (Santiago, Editorial Jurídica de Chile, 2004).

TARELlo, Giovanni, Storia della cultura giuridica moderna (Bologna, Il Mulino, 1976).

Tarello, Giovanni, Sul problema della crisi nel diritto (Torino, Giappichelli, 1957).

TARuffo, Michele - HaZArd, Geoffrey (editores) Abuse of Procedural Rights: Comparative Standards of Procedural Fairness (New Orleans, Tulane Law School, 1999).

Taruffo, Michele, L'abuso del processo: profili comparatistici, en Revista Do Proceso,, 96 (Sao Paulo, Editora Dos tribunais, 1999).

TARUffo, Michele, Senso comun, experiencia e ciéncia no raciocinio do juiz, en Revista de la Universidad Federal do Paraná, (2001).

Tesoriere, Giovanni, Contributo allo studio delle preclusioni nel proceso civile (Padova, Cedam, 1983).

TiRANTI, V. E., Ricerche sulla struttura orgánica del processo civile (Pisa, Spoerri editore, 1904).

Troller, Alois, Dos fundamentos do formalismo processual civil (Porto Alegre, Sergio Antonio Fabris, 2009).

Turner SAelzer, Susan, Los tribunales de familia, en Ius et Praxis, 82 (2002) 28. 
VAn Rhee, C. H., Public and Private Justice: History and Development, en VAN RheE, C. H. - Uzelac, A., (editores.), Public and Private Justice, Dispute Resolution in Modern Societies (Intersentia, Atwerpen - Oxford, 2007).

Vargas Pavez, Macarena - Correa Camus, Paula, La voz de los niños en la justicia de familia de Chile, en Revista Ius et Praxis, 17 (2011) 1.

WACH, Adolf, Conferencias sobre la Ordenanza Procesal Civil (Lima, Ara, 2006). 
